\title{
Static magnetowetting of ferrofluid drops
}

\section{Carlo Rigoni ${ }^{\text {a }}$, Matteo Pierno ${ }^{a}$, Giampaolo Mistura ${ }^{\text {a,* }}$ \\ Delphine Talbot ${ }^{\mathrm{b}}$, Jean-Claude Bacri $^{\mathrm{c}}$, René Massart ${ }^{\mathrm{b}}$, Ali Abou-Hassan ${ }^{\mathrm{b}},{ }^{*}$}

${ }^{a}$ Dipartimento di Fisica e Astronomia G.Galilei, Università di Padova, via Marzolo 8, 35131 Padova (Italy)

${ }^{\mathrm{b}}$ Sorbonne Universités, UPMC Univ Paris 06, UMR 8234 CNRS, Laboratoire PHysico-chimie des Electrolytes et Nanosystèmes InterfaciauX (PHENIX), 4 place Jussieu - case 51,75005 Paris (France).

${ }^{\mathrm{c}}$ Laboratoire Matière et Systèmes Complexes (MSC), UMR 7057, CNRS and Université Paris Diderot, 75205 Paris (France)

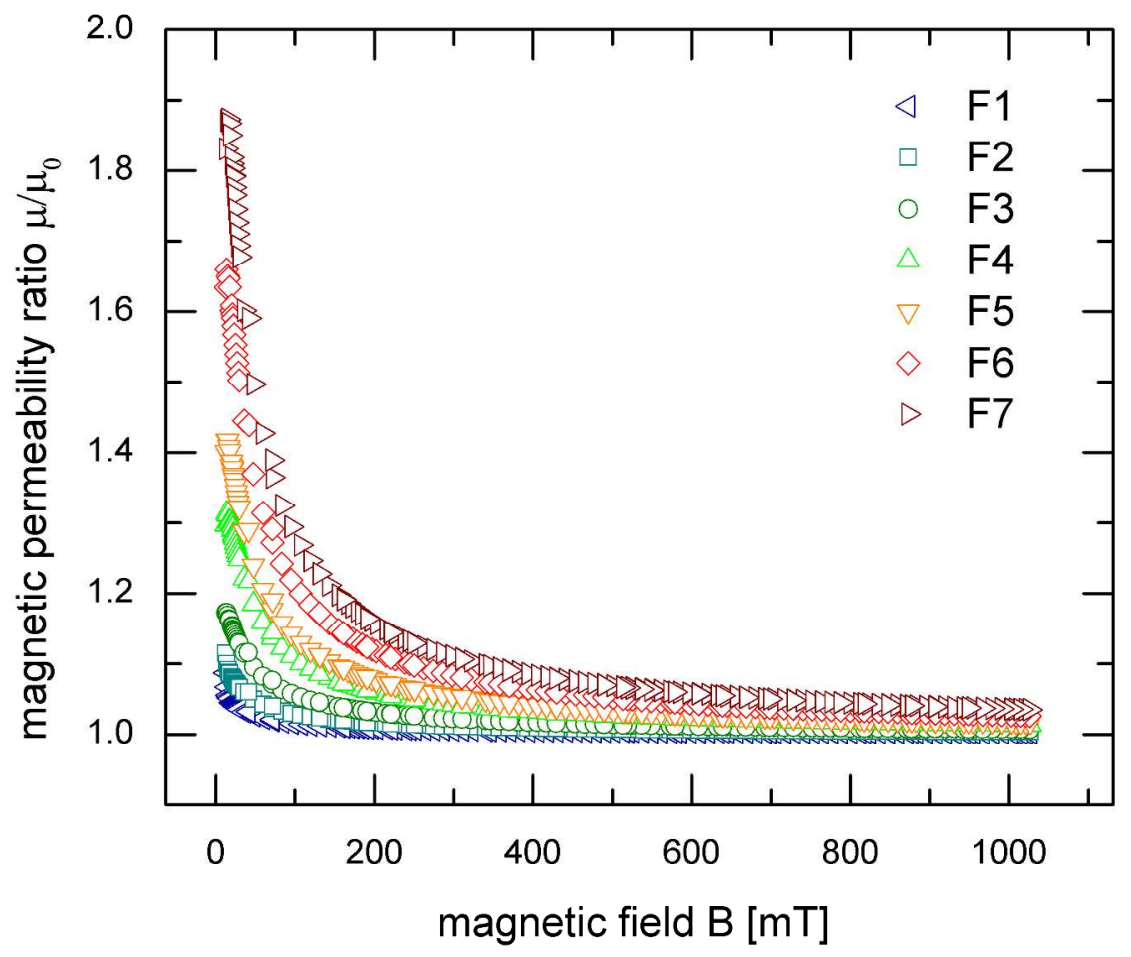

Figure S1. Magnetic permeability ratio $\left(\boldsymbol{\mu} / \boldsymbol{\mu}_{\mathbf{0}}\right)$ curves at $285 \mathrm{~K}$ of the different ferrofluids used in our experiments. The iron concentrations and the magnetic susceptibilities $(\chi)$ of the different ferrofluids are: $\mathrm{F} 1=0.2 \mathrm{~mol} / \mathrm{L}, \chi_{\mathrm{F} 1}=0.042 ; \mathrm{F} 2=0.4$ $\mathrm{mol} / \mathrm{L}, \chi_{\mathrm{F} 2}=0.144 ; \mathrm{F} 3=0.8 \mathrm{~mol} / \mathrm{L}, \chi_{\mathrm{F} 3}=0.144 ; \mathrm{F} 4=1.5 \mathrm{~mol} / \mathrm{L}, \chi_{\mathrm{F} 4}=0.28 ; \mathrm{F} 5=2.0 \mathrm{~mol} / \mathrm{L}, \chi_{\mathrm{F} 5}=0.35 ; \mathrm{F} 6=3.0 \mathrm{~mol} / \mathrm{L}, \chi_{\mathrm{F} 6}=$ $0.57 ; \mathrm{F} 7=4.0 \mathrm{~mol} / \mathrm{L}, \chi_{\mathrm{F} 7}=0.74$ 


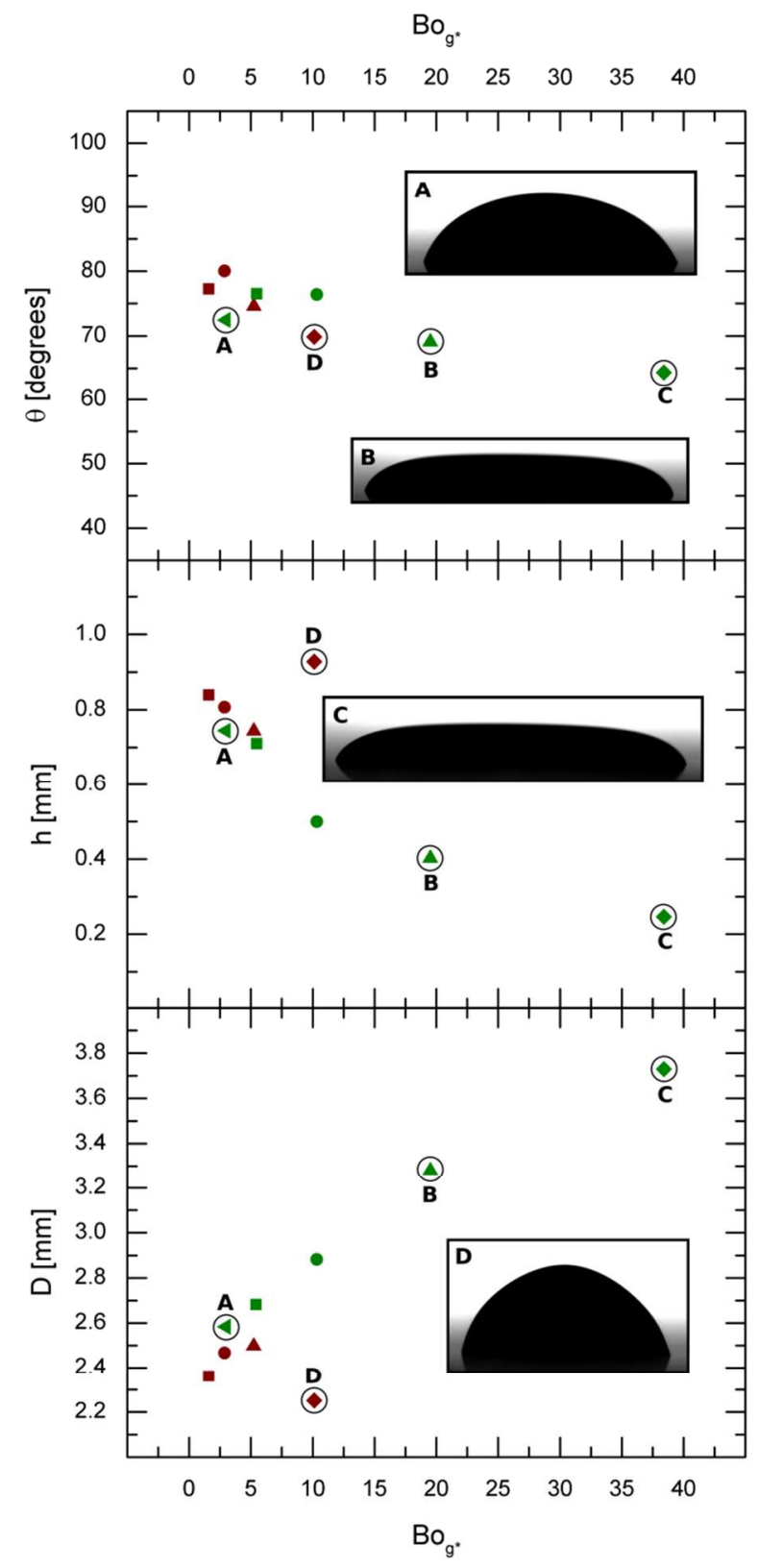

Figure S2. Contact angle (top), maximum height (middle) and diameter of the contact line (bottom) of ferrofluid drops of volume $V=2.5 \mu \mathrm{L}$ as a function of the effective Bond number. The symbols represent different concentrations of the ferrofluidic solutions: $\triangleleft 0.2 \mathrm{~mol} / \mathrm{L}, \square 0.4 \mathrm{~mol} / \mathrm{L}, \bigcirc 0.8 \mathrm{~mol} / \mathrm{L}, \triangle 1.5 \mathrm{~mol} / \mathrm{L}, \diamond 3 \mathrm{~mol} / \mathrm{L}$. Different colors are associated to the magnets according to the following palette: magnet M1 and magnet M2. The drops are deposited on a NOA coated glass slide. 


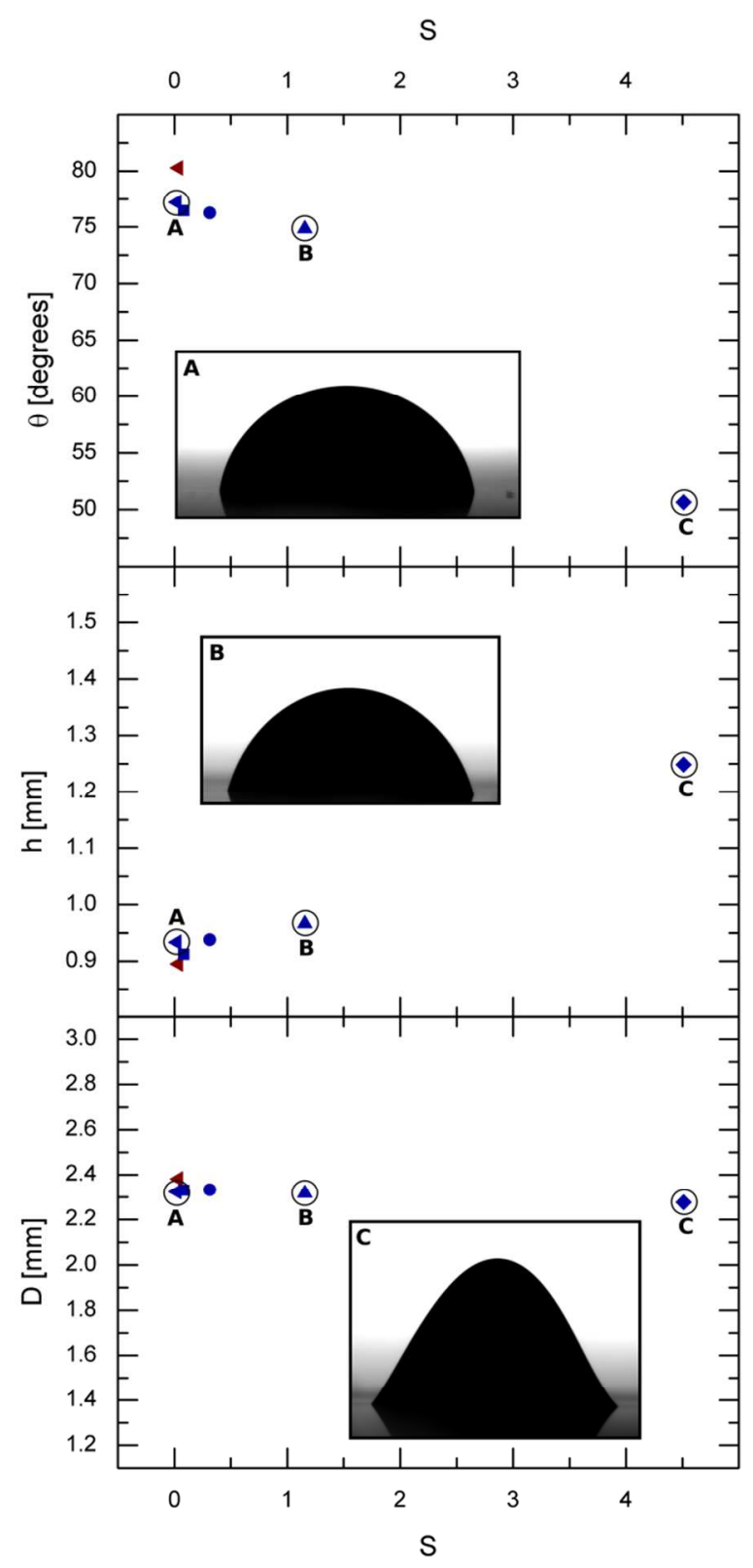

Figure S3. Contact angle (top), maximum height (middle) and diameter of the contact line (bottom) of ferrofluid drops of volume $V=2.5 \mu \mathrm{L}$ as a function of the $\mathrm{S}$ number. The symbols represent different concentrations of the ferrofluid solutions: $\triangleleft 0.2 \mathrm{~mol} / \mathrm{L}, \square 0.4 \mathrm{~mol} / \mathrm{L}, \bigcirc 0.8 \mathrm{~mol} / \mathrm{L}, \triangle 1.5 \mathrm{~mol} / \mathrm{L}, \diamond 3 \mathrm{~mol} / \mathrm{L}, \triangleright 4 \mathrm{~mol} / \mathrm{L}$. Different colors are associated to the magnets according to the following palette: magnet M1 and magnet M5. The drops are deposited on a NOA coated glass slide. 


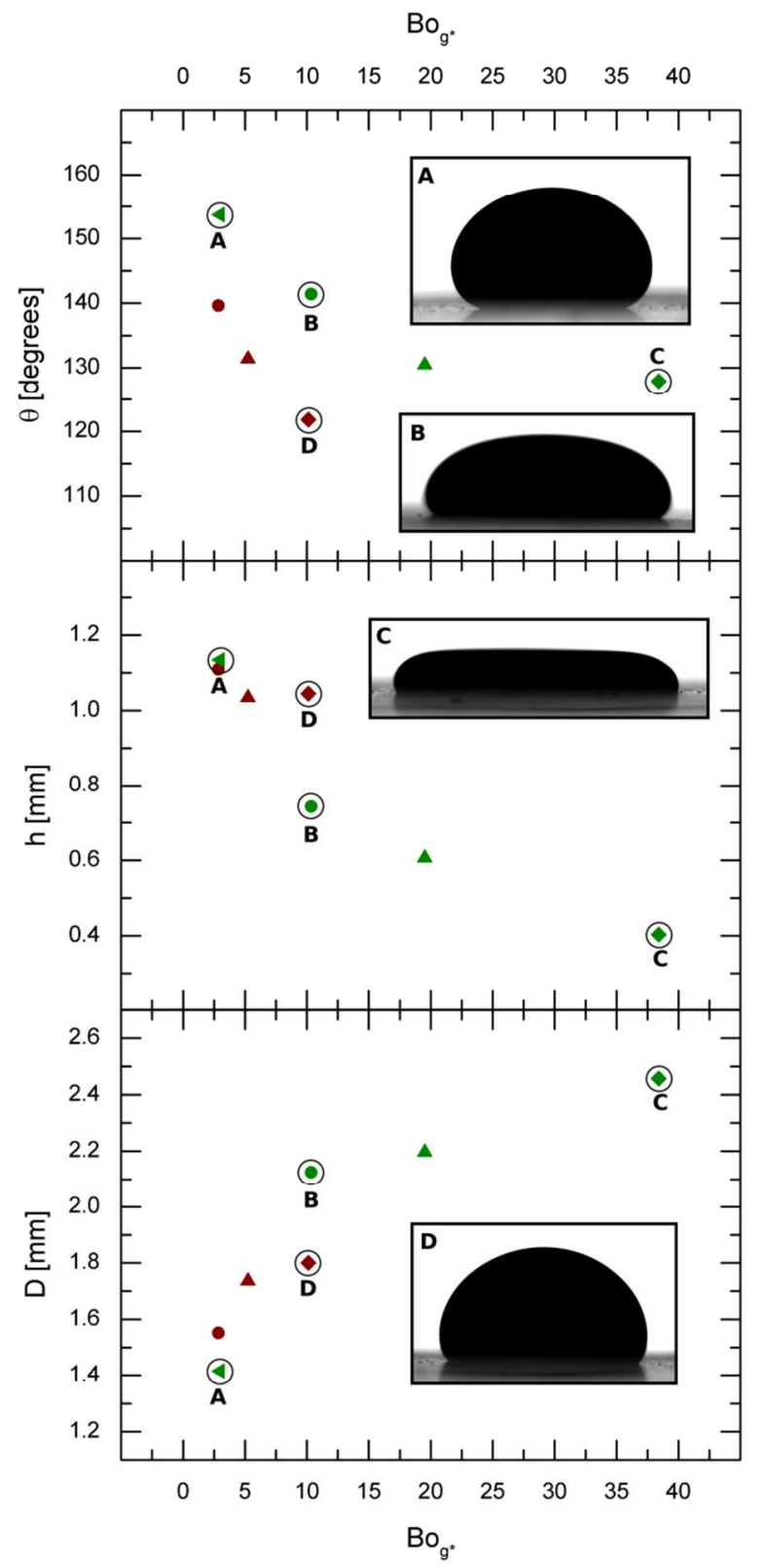

Figure S4. Contact angle (top), maximum height (middle) and diameter of the contact line (bottom) of ferrofluid drops of volume $V=2.5 \mu \mathrm{L}$ as a function of the effective Bond number. The symbols represent different concentrations of the ferrofluidic solutions: $\triangleleft 0.2 \mathrm{~mol} / \mathrm{L}, \bigcirc 0.8 \mathrm{~mol} / \mathrm{L}, \triangle 1.5 \mathrm{~mol} / \mathrm{L}, \diamond 3 \mathrm{~mol} / \mathrm{L}$. Different colors are associated to the magnets according to the following palette: superhydrophobic coated glass slide. 
S

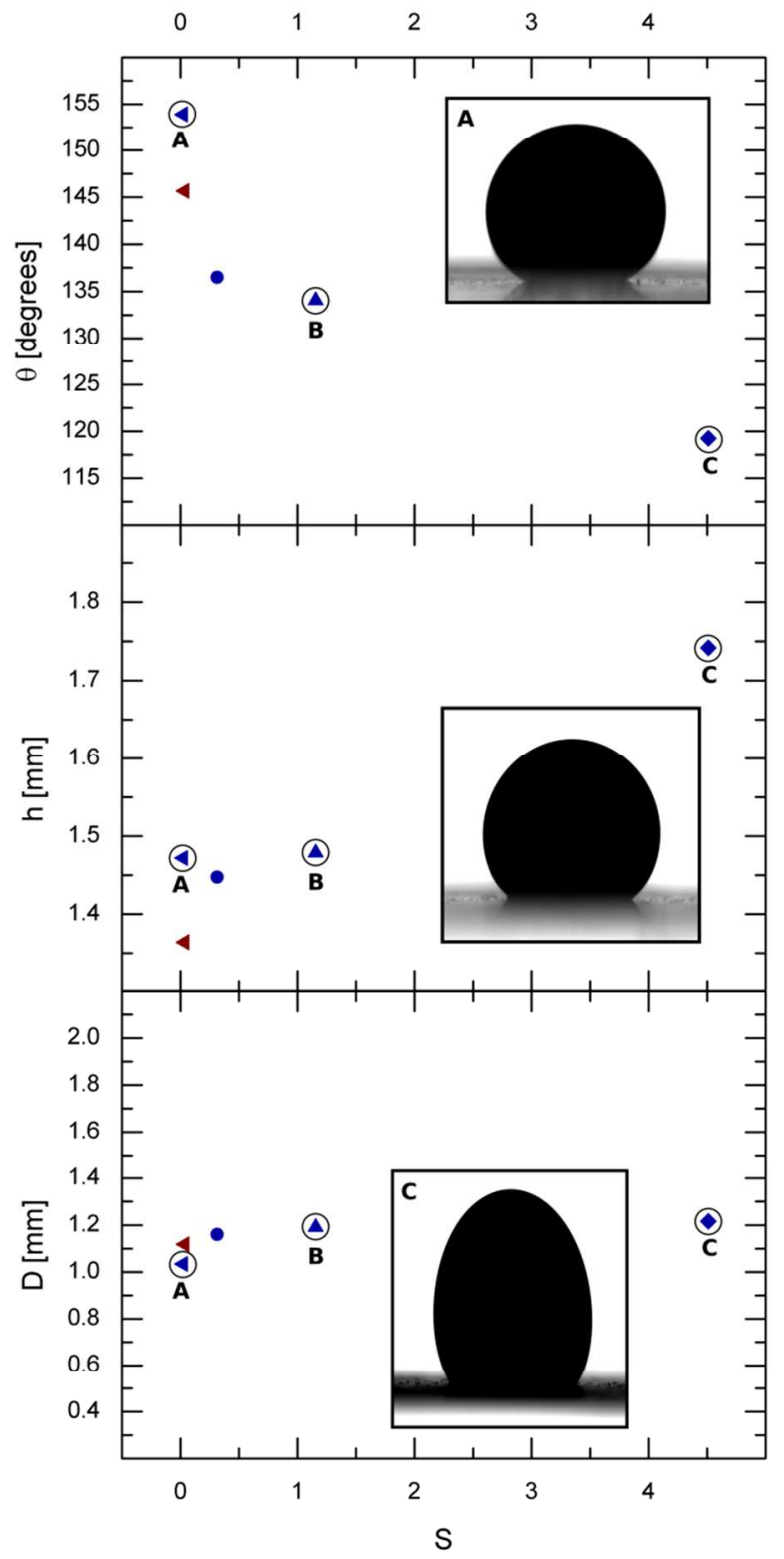

Figure S5. Contact angle (top), maximum height (middle) and diameter of the contact line (bottom) of ferrofluid drops of volume $V=2.5 \mu \mathrm{L}$ as a function of the $\mathrm{S}$ number. The symbols represent different concentrations of the ferrofluid solutions: $\triangleleft 0.2 \mathrm{~mol} / \mathrm{L}, \circ 0.8 \mathrm{~mol} / \mathrm{L}, \triangle 1.5 \mathrm{~mol} / \mathrm{L}, \diamond 3 \mathrm{~mol} / \mathrm{L}, \triangleright 4 \mathrm{~mol} / \mathrm{L}$. Different colors are associated to the magnets according to the following palette: magnet M1 and magnet M5. The drops are deposited on a nearly superhydrophobic coated glass slide. 